\title{
Pharmacologic Management of Atrial Fibrillation: Established and Emerging Options
}

\author{
James S. Kalus, PharmD, BCPS
}

\begin{abstract}
BACKGROUND: In patients with atrial fibrillation (AF), antiarrhythmic drug therapy currently plays a greater role in maintaining sinus rhythm after cardioversion than it does in converting AF to sinus rhythm. Amiodarone is the most effective antiarrhythmic agent for maintaining sinus rhythm after cardioversion in patients with AF. However, its pharmacokinetics is complex; the drug interacts with many commonly used medications; and long-term use can cause thyroid dysfunction, hepatotoxicity, and other severe extracardiac adverse effects. The use of antiarrhythmic strategies in patients with AF has decreased because of evidence of greater safety and lower costs for hospitalization obtained from the use of rate-control strategies instead. Nevertheless, some patients require a rhythm-control strategy. Warfarin is used to prevent embolic stroke in many patients with AF, but its use is also complex and requires monitoring. Therefore, efforts have been made to develop antiarrhythmic agents with improved tolerability and anticoagulants that are easy to use.

OBJECTIVES: To describe the 3 primary goals of pharmacotherapy in patients with AF, compare and contrast the efficacy and safety of established and investigational pharmacotherapies for $\mathrm{AF}$, and recommend a drug regimen for an individual with AF based on patient-specific factors.

SUMMARY: Currently available antiarrhythmic agents differ in their efficacy for maintaining sinus rhythm after cardioversion in AF patients with tolerability problems, comorbidities (particularly heart failure and renal impairment), and potential drug interactions. Hence, when selecting drug therapy to maintain sinus rhythm after cardioversion, it is important to take into consideration patient characteristics, including age, disease states, renal function, and concurrent drug therapies. Outpatient self-administration of single loading doses of flecainide or propafenone with what is referred to as the pill-inthe-pocket approach may be considered for carefully selected patients with recurrent episodes of symptomatic AF. The recently approved antiarrhythmic agent dronedarone has electrophysiologic properties similar to those of amiodarone, but its lack of iodine may improve upon the pharmacokinetic and tolerability issues associated with amiodarone. Vernakalant is another investigational antiarrhythmic agent that may prove useful for cardioversion and maintenance of sinus rhythm after cardioversion in patients with AF. New oral anticoagulants that do not require close laboratory monitoring and are simpler to use than warfarin have been used investigationally for prevention of venous thromboembolism and are in clinical trials for prevention of embolic stroke in patients with AF.
\end{abstract}

CONCLUSIONS: Pharmacotherapy for patients with AF should be individualized based on patient-specific factors. New therapeutic options may become available to facilitate treatment of these patients.

J Manag Care Pharm. 2009;15(6-b)(Suppl):S10-S18

Copyright $\odot$ 2009, Academy of Managed Care Pharmacy. All rights reserved.

Author

JAMES S. KALUS, PharmD, BCPS, at the writing of this article was Senior Manager, Patient Care Services, Department of Pharmacy Services, Henry Ford Hospital, Detroit, Michigan.

AUTHOR CORRESPONDENCE: James S. Kalus, PharmD, BCPS, Senior Manager, Patient Care Services, Department of Pharmacy Services, Henry Ford Hospital, 2045 W. Grand Blvd., Detroit, MI 48202. Tel: 313.916.7755; Fax: 313.916.1302,

E-mail: jkalus1@hfhs.org

\section{DISCLOSURES}

This learning activity was sponsored by an educational grant from sanofiaventis U.S. Kalus reports no conflicts of interest related to the subject of this article. He received an honorarium for his participation in the online symposium and for the preparation of this article.

Susan R. Dombrowski, MS, RPh, provided assistance with the medical writing, and Catherine N. Klein, RPh, and Carla J. Brink, MS, RPh, provided editorial assistance.

Off-Label Disclosure Statement

In this article, the following off-label use of antiarrhythmic agents is discussed: disopyramide and amiodarone for the treatment of atrial fibrillation. Dronedarone was recently approved by the FDA for use in patients with atrial fibrillation who do not have severe heart failure.

A trial fibrillation (AF) is associated with substantial morbidity and mortality and negatively impacts quality of life. Pharmacologic agents are used in the management of atrial fibrillation for prevention of embolic stroke, control of ventricular rate, and restoration and maintenance of normal sinus rhythm. ${ }^{1}$ Optimization of therapy for the patient with AF requires the pharmacist to consider patient comorbidities, medication efficacy, and medication toxicities when designing a treatment regimen and monitoring plan. While currently available agents used in the management of AF have substantial limitations in terms of both safety and efficacy, new therapeutic options may soon become available.

\section{Antithrombotic Therapy}

The decision to use antithrombotic therapy and the type of antithrombotic therapy selected to prevent thromboembolic events in patients with AF are based on the risks and benefits of such therapy and the risk of stroke. The $\mathrm{CHADS}_{2}$ risk scoring system is used to determine the risk for stroke in patients with $\mathrm{AF}^{2}{ }^{2}$ Warfarin is used in patients at high or intermediate risk for stroke, but its use is complicated by a narrow therapeutic index, risk for bleeding, and the continuous need for laboratory monitoring. ${ }^{3}$ Aspirin is recommended for patients at low or intermediate risk for stroke. Overall, aspirin is less effective than warfarin for the prevention of stroke in patients with $\mathrm{AF}^{3}$

\section{Rate Versus Rhythm Control}

There are 2 phases to ventricular rate control in patients with AF. Acute ventricular rate control is provided to reduce heart rate and control symptoms at the time of initial patient presentation. Chronic ventricular rate control is provided as a long-term maintenance strategy. Acute ventricular rate control usually involves the intravenous use of a nondihydropyridine calcium channel blocker (e.g., diltiazem or verapamil), $\beta$-blocker, or digoxin. When a long-term rate control strategy will be used to manage 
a patient with $\mathrm{AF}$, the patient is allowed to remain in $\mathrm{AF}$, and the heart rate is maintained at a target of less than 80 beats per minute (at rest) or 100 beats per minute (with exercise) using an oral nondihydropyridine calcium channel blocker, $\beta$-blocker, or digoxin. ${ }^{1}$ Underlying disease states and blood pressure should be considered when selecting drug therapy for acute and chronic rate control. For example, digoxin could be used as a rate-controlling agent in patients with underlying systolic heart failure. Digoxin could also be a useful option when blood pressure is low. ${ }^{1}$

Rhythm control involves restoring and maintaining sinus rhythm through the use of antiarrhythmic drugs, electrical cardioversion, or both. There has been considerable debate about the comparative efficacy and cost of rate-control and rhythmcontrol strategies. Study results suggest that mortality, quality of life, and health care costs are similar regardless of which strategy is used. ${ }^{1,4-6}$ In 1 of the largest randomized studies that enrolled 4,060 patients with AF and at least 1 risk factor for stroke (Atrial Fibrillation Follow-Up Investigation of Rhythm Management [AFFIRM] trial), there was no significant difference in mortality between the rate-control (25.9\%) and rhythm-control (26.7\%) groups $(P=0.08) .{ }^{4}$ The incidence of ischemic stroke, a secondary endpoint, also was similar in the 2 groups ( $5.5 \%$ with rate control vs. $7.1 \%$ with rhythm control, $P=0.79$ ). The incidence of torsades de pointes, which is a ventricular tachyarrhythmia with QT interval prolongation, was significantly lower with rate control (0.2\%) than with rhythm control $(0.8 \%, P=0.007)$. Pulmonary and gastrointestinal events, bradycardia, and prolongation of the QT interval on the electrocardiogram (ECG) also were significantly less common in the rate-control group than in the rhythmcontrol group $(P<0.001)$. The incidence of hospitalization during follow-up was significantly lower with rate control compared with rhythm control $(73.0 \%$ and $80.1 \%$, respectively, $P<0.001)$.

Findings of the AFFIRM study and other rate versus rhythm studies suggesting greater safety and lower costs for hospitalization from the use of rate-control strategies compared with rhythm-control strategies has led to a reduction in the use of rhythm-control strategies in patients with $\mathrm{AF}{ }^{7,8}$ However, studies comparing rate- and rhythm-control strategies might be limited by the fact that these studies enrolled a mostly elderly and sedentary patient population. Also, an initial criticism of AFFIRM was that the study included few patients with heart failure, a group commonly afflicted with AF. However, the Atrial Fibrillation and Congestive Heart Failure study also demonstrated similar outcomes between a rate- and rhythm-control strategy, echoing the results of AFFIRM. ${ }^{9}$

Patients presenting with hemodynamic instability require rhythm control and should immediately undergo electrical cardioversion. ${ }^{1}$ If a patient is hemodynamically stable, the clinician can take some time deciding on a therapeutic strategy (i.e., rate control vs. rhythm control, and pharmacotherapy vs. electrical cardioversion to achieve rhythm control if that strategy is selected). ${ }^{1}$
The use of rhythm-control strategies is limited by the toxicity of many antiarrhythmic drugs and higher rate of hospitalization. ${ }^{1,4}$ Nevertheless, rhythm-control interventions may be required for patients whose heart rate remains elevated ( $>80$ beats per minute) despite the use of rate-control strategies; patients who remain symptomatic despite effective ventricular rate control $(<80$ beats per minute); and patients who are physically active and have poor exercise tolerance with the use of rate-control strategies. ${ }^{1}$

Drug therapy plays a minimal role in acute conversion of AF to sinus rhythm because electrical cardioversion is more effective than pharmacologic cardioversion with success rates of $90 \%$ and approximately $40 \%$, respectively. ${ }^{10}$ Nevertheless, drug therapy may play a role before and after electrical cardioversion to improve the likelihood of successful conversion to and maintenance of sinus rhythm. ${ }^{1}$ The rate of recurrence of AF (i.e., relapse) after conversion to sinus rhythm is high, with only about $15 \%$ of patients remaining in sinus rhythm 1 year after electrical cardioversion. ${ }^{1,11-13}$

Class I and class III antiarrhythmic agents are the primary pharmacologic agents used for achieving rhythm control in patients with AF. Patterns of use of these agents have changed in recent years. The use of class Ia agents, particularly quinidine, decreased between 1991 and 2000.13 The oral formulation of the class Ia antiarrhythmic agent procainamide was recently withdrawn from the market because of lack of use. There has also been a small decline in the use of class Ic antiarrhythmic agents (e.g., flecainide and propafenone). By contrast, in the 1990s there was a considerable increase in the use of the class III agents amiodarone and sotalol, which are the most commonly used antiarrhythmic drugs for $\mathrm{AF}^{13}$ Changes in use patterns for the various antiarrhythmic drugs have likely resulted from concerns about drug toxicities and efficacy considerations that will be discussed below.

\section{Class la and Ic Agents}

The class Ia antiarrhythmic agents disopyramide and quinidine and class Ic antiarrhythmic agents flecainide and propafenone are used less often than class III drugs in patients with AF primarily because of their potential adverse effects. Disopyramide is not approved by the U.S. Food and Drug Administration (FDA) for the treatment of AF (quinidine, flecainide, and propafenone are FDA-approved for AF). ${ }^{14}$ All of these agents are associated with a risk of proarrhythmia. The tolerability of disopyramide and quinidine is particularly poor. Anticholinergic adverse effects (e.g., urinary retention, dry mouth) are associated with disopyramide, and rash, photosensitivity, and gastrointestinal adverse effects (e.g., diarrhea, abdominal pain, and cramps) can occur with quinidine.,15 Flecainide and propafenone are better tolerated than disopyramide and quinidine, but these class Ic antiarrhythmic agents are not safe to use in patients with structural heart disease (e.g., coronary heart disease, left ventricular hypertrophy, heart failure, valvular dysfunction) because they can increase mortality. ${ }^{16-18}$ 


\begin{tabular}{|c|c|c|}
\hline $\begin{array}{l}\text { Antiarrhythmic } \\
\text { Drug Class or Agent }\end{array}$ & $\begin{array}{l}\text { Efficacy Assessment } \\
\text { and Advantages }\end{array}$ & Disadvantages \\
\hline \multicolumn{3}{|l|}{ Class Ia } \\
\hline Disopyramide $^{a}$ & Low efficacy & $\begin{array}{l}\text { Proarrhythmia (torsades } \\
\text { de pointes) } \\
\text { Anticholinergic adverse } \\
\text { effects }\end{array}$ \\
\hline Quinidine & Low efficacy & $\begin{array}{l}\text { Proarrhythmia (torsades } \\
\text { de pointes) } \\
\text { Gastrointestinal adverse } \\
\text { effects }\end{array}$ \\
\hline \multicolumn{3}{|l|}{ Class Ic } \\
\hline Flecainide & Modest efficacy & $\begin{array}{l}\text { Proarrhythmias } \\
\text { Not safe in structural } \\
\text { heart disease } \\
\text { Drug interactions }\end{array}$ \\
\hline Propafenone & Modest efficacy & $\begin{array}{l}\text { Proarrhythmia } \\
\text { Nonselective } \beta \\
\text { blockade (bradycardia, } \\
\text { exacerbation of chronic } \\
\text { obstructive pulmonary } \\
\text { disease) } \\
\text { Not safe in structural } \\
\text { heart disease } \\
\text { Drug interactions }\end{array}$ \\
\hline \multicolumn{3}{|l|}{ Class III } \\
\hline Amiodaronea & $\begin{array}{l}\text { High efficacy } \\
\text { Low risk of } \\
\text { proarrhythmia } \\
\text { Safe in heart failure }\end{array}$ & $\begin{array}{l}\text { Extracardiac effects } \\
\text { Drug interactions }\end{array}$ \\
\hline Sotalol & $\begin{array}{l}\text { Modest efficacy } \\
\text { Not expected to interact } \\
\text { with drugs metabolized } \\
\text { by CYP enzymes }\end{array}$ & $\begin{array}{l}\text { Nonselective } \beta \\
\text { blockade (bradycardia, } \\
\text { exacerbation of chronic } \\
\text { obstructive pulmonary } \\
\text { disease) } \\
\text { Proarrhythmia (torsades } \\
\text { de pointes) } \\
\text { Eliminated renally } \\
\text { Inpatient initiation }\end{array}$ \\
\hline Dofetilide & $\begin{array}{l}\text { Modest efficacy } \\
\text { Safe in heart failure } \\
\text { Generally well tolerated } \\
\text { (except for torsades de } \\
\text { pointes) }\end{array}$ & $\begin{array}{l}\text { Proarrhythmia (torsades } \\
\text { de pointes) } \\
\text { Eliminated renally } \\
\text { Drug interactions } \\
\text { Inpatient initiation } \\
\end{array}$ \\
\hline
\end{tabular}

${ }^{a}$ Not approved by the U.S. Food and Drug Administration for atrial fibrillation. Sources $=$ references. $1,13 a ̊ 15-32$

\section{Class III Agents}

\section{Amiodarone}

Amiodarone is the most commonly used antiarrhythmic drug in patients with AF, largely because it is the most effective agent for maintaining sinus rhythm (an indication not approved by the FDA) and has a low risk of proarrhythmic effects (Table 1).,19,20 Amiodarone does not increase mortality in patients with heart failure; therefore, it is safe to use in this patient population. ${ }^{21-24}$

Nevertheless, amiodarone is among the most toxic antiarrhythmic agents; it is associated with a high incidence of potentially severe extracardiac effects. ${ }^{1}$ These effects include neuropathy, thyroid dysfunction (a common effect manifesting as either hypothyroidism or hyperthyroidism), pulmonary fibrosis (a rare but potentially serious complication), hepatotoxicity, rash or photosensitivity, blue-grey skin discoloration, and ophthalmic effects (corneal deposits and optic neuritis). ${ }^{1}$ These extracardiac effects may not be observed during initial therapy; however, the risk increases after more than 6 months of treatment. ${ }^{1}$

The pharmacokinetics of amiodarone are complex. The drug has a long half-life, which complicates loading dosing, adverse effect management, and transition from amiodarone to another antiarrhythmic drug. ${ }^{25}$ Amiodarone also has a large volume of distribution into a wide variety of tissues, including extracardiac tissues, which accounts for the relatively high incidence of extracardiac adverse effects associated with this drug.

The potential for drug interactions is an important consideration in the use of amiodarone. Many of these interactions are mediated by cytochrome P-450 (CYP) drug-metabolizing enzymes, specifically potent inhibition of the CYP1A2, 2C9, 2D6, and 3A4 enzymes, which are responsible for significant clinical interaction with drugs such as simvastatin and warfarin. ${ }^{26}$ Another method by which amiodarone can cause interactions is via transporter-based mechanisms; for example, digoxin inhibits the P-glycoprotein membrane transporter, resulting in increased serum drug concentrations and a potential risk of increased toxicity. ${ }^{25,26}$

\section{Sotalol}

Sotalol is a commonly used class III antiarrhythmic agent that is approved by the FDA for the maintenance of normal sinus rhythm in patients with symptomatic AF/atrial flutter who are currently in sinus rhythm. ${ }^{27}$ Its efficacy in maintaining sinus rhythm is only modest. ${ }^{1}$

Because sotalol is eliminated renally, dosage reduction is required for patients with renal impairment. Proarrhythmia is the major side effect from sotalol. The incidence of torsades de pointes associated with the use of sotalol in patients with $\mathrm{AF}$ or other supraventricular arrhythmias ranges from $0.3 \%$ to $3.2 \%$, depending on dosage. ${ }^{28}$ The likelihood of proarrhythmia also depends on patient characteristics (e.g., sex, heart failure, renal function). To minimize the risk of proarrhythmia, sotalol therapy should be initiated on an inpatient basis. ${ }^{1}$ The adverse 
effect profile of sotalol primarily reflects its $\beta$-blocking properties (e.g., asthma, bradycardia, exacerbation of chronic obstructive pulmonary disease). ${ }^{1}$ Sotalol is neither metabolized by, nor is it an inducer or inhibitor of, the CYP enzyme system.

\section{Dofetilide}

Dofetilide, a class III antiarrhythmic agent, has been available for approximately 10 years. It is indicated for the maintenance of normal sinus rhythm in patients with AF/atrial flutter of greater than one week duration who have been converted to normal sinus rhythm. It is modestly effective for conversion and maintenance of sinus rhythm in patients with AF. ${ }^{29,30}$ Like amiodarone, this drug does not increase mortality and is considered safe to use in patients with heart failure. ${ }^{31}$

Dofetilide is generally well tolerated; however, torsades de pointes is the adverse effect of primary concern. ${ }^{32}$ The incidence of torsades de pointes in dofetilide clinical trials ranged from $0.3 \%$ to $4.7 \%$, depending on dosage and patient characteristics (e.g., sex, renal function). ${ }^{1}$ As with sotalol, the kidneys play an important role in elimination of dofetilide; therefore, dosage reduction is required for patients with renal impairment. Additionally, initiation of therapy should be performed on an inpatient basis to minimize the risk of proarrhythmia. ${ }^{30}$

Dofetilide is associated with numerous drug interactions. Its use concomitantly with verapamil, hydrochlorothiazide, ketoconazole, cimetidine, or trimethoprim is contraindicated because of the potential for increased dofetilide plasma concentrations and increased risk of torsades de pointes..$^{33}$ The concurrent use of dofetilide and drugs that prolong the QT interval (e.g., phenothiazines) is not recommended due to the risk for additive QT prolongation.

\section{Comparative Efficacy and Safety}

In a meta-analysis, all of the class Ia, Ic, and III agents listed in Table 1 reduced the risk of recurrence of AF in patients in whom sinus rhythm had been restored. ${ }^{34}$ Amiodarone was most effective, and the class Ia agents were least effective.

Many comparative studies use both efficacy for maintaining sinus rhythm and adverse effects as endpoints in patients with AF. In 1 such study of 254 patients, propafenone was more effective than sotalol with fewer adverse effects..$^{35}$ In another study of 665 patients, amiodarone and sotolol were similarly effective for conversion of atrial fibrillation and amiodarone was more effective than sotalol for maintaining sinus rhythm. ${ }^{36}$ There was no significant difference between the 2 drugs in major adverse effects. In another study, amiodarone was more effective than propafenone in maintaining sinus rhythm after conversion in 146 patients with recurrent symptomatic AF, but propafenone caused fewer adverse effects. ${ }^{37}$ The safety advantage of propafenone outweighed the greater efficacy of amiodarone. While few studies directly compare different antiarrhythmic agents, it is clear that consideration of both efficacy and safety is critical when selecting therapy.

\section{Pill-in-the-Pocket Approach}

Certain patients with recurrent episodes of symptomatic AF may be candidates for outpatient self-administration of single loading doses of flecainide or propafenone using what is referred to as the "pill-in-the-pocket" approach to terminating AF. ${ }^{1}$ The efficacy and safety of this approach were demonstrated in 210 patients with mild or no heart disease who came to the emergency room with recent-onset AF that was hemodynamically well tolerated. ${ }^{38}$ If flecainide or propafenone was successful in converting the patient from AF in the emergency room, they were eligible for inclusion in the study. Included patients were advised to take a dose of flecainide or propafenone 5 minutes after the onset of palpitations on an outpatient basis. The mean duration of followup was 15 months. Treatment was successful in 534 (94\%) of 569 episodes. Compared with the year before study enrollment, there were significantly fewer visits to the emergency room each month ( 4.9 vs. $45.6, P<0.001)$ and hospitalizations each month (1.6 vs. 15.0, $P<0.001)$ during the follow-up period. These large reductions in emergency room visits and hospitalization occurred even though there was no significant difference in the mean number of symptomatic episodes per month before and after study enrollment (59.8 and 54.5, respectively). The most recent AF treatment guidelines recommend that this pill-in-the-pocket approach be used if the patient has had a safe response to single-dose therapy as an inpatient. However, this strategy should be avoided in patients without sinus or AV node dysfunction, bundle-branch block, QT-interval prolongation, the Brugada syndrome (a hereditary arrhythmia), or structural heart disease. ${ }^{1}$

\section{Inpatient Initiation}

Because antiarrhythmic drugs can be proarrhythmic, 1 strategy to minimize risk with these agents is to initiate the drug in a hospital or other facility where continuous ECG monitoring, creatinine clearance $(\mathrm{CrCl})$ calculation, and cardiac resuscitation are available..$^{28,30}$ Inpatient initiation is required for both dofetilide and sotalol but is often used for other agents as well. ${ }^{27,33}$ For inpatient initiation, patients should be admitted for at least 3 days. Calculation of the $\mathrm{CrCl}$ should be performed, and dosage reductions should be made in patients with renal dysfunction. Potassium and magnesium serum concentrations should be monitored, and electrolyte replacement should be provided as needed. The corrected QT (QTc) interval should be measured at baseline to ensure that it is within normal limits $(450 \mathrm{msec}$ or less for sotalol and $440 \mathrm{msec}$ or less for dofetilide) before initiating either of these antiarrhythmics. ${ }^{27,33}$ The QTc interval should be checked several hours after each dose because dosage adjustment or discontinuation of drug therapy may be required if the QTC interval is excessively prolonged. If AF persists for more than 3 days, electrical cardioversion should be attempted to restore sinus rhythm. ${ }^{27,33}$ 


\section{Emerging Agents}

Problems with proarrhythmia, particularly torsades de pointes, and hospitalization because of AF recurrence or extracardiac toxicities have hindered the use of rhythm-control strategies in patients with AF. ${ }^{8}$ Efforts to develop new antiarrhythmic agents with improved safety and tolerability could cause clinicians to reexamine the debate about rate control versus rhythm control.

\section{Dronedarone}

Dronedarone is a recently FDA-approved antiarrhythmic agent with electrophysiologic effects that are similar to those of amiodarone, although dronedarone may be less likely to prolong the QT interval. ${ }^{39,40}$ The chemical structure of dronedarone differs from that of amiodarone in its lack of iodine, which could minimize the impact of dronedarone on thyroid function. The lack of iodine also could make dronedarone less lipophilic and limit its distribution and potential for extracardiac toxicities. ${ }^{40}$

Dronedarone has a considerably shorter half-life than amiodarone (1-2 days vs. 30-55 days), which could make dosing more reliable and facilitate the use of loading doses. ${ }^{40}$ Like amiodarone, dronedarone is a CYP3A4 substrate and inhibits CYP2D6; therefore, interactions with drugs metabolized by these isoenyzmes could occur. ${ }^{41,42}$

Dronedarone has been extensively studied in several phase III randomized, double-blind, placebo-controlled studies. All of these studies involved a dosage of $400 \mathrm{mg}$ orally twice daily, but the patient inclusion and exclusion criteria varied.

The first reported clinical trial results were from 2 identical trials known as EURIDIS (EURopean trial In atrial fibrillation patients receiving Dronedarone for the maintenance of Sinus rhythm) and ADONIS (American-Australian-African trial with Dronedarone In atrial fibrillation patients for the maintenance of Sinus rhythm) that involved a total of 1,237 patients with paroxysmal or persistent (i.e., lasting less than 12 months) $\mathrm{AF}$ or atrial flutter. ${ }^{43}$ Patients with New York Heart Association (NYHA) class III or IV HF were excluded from both studies. One study (EURIDIS) was conducted in Europe, and the other study (ADONIS) was conducted in the United States and other nonEuropean countries. Patients were randomly assigned in a 2:1 ratio to receive dronedarone $400 \mathrm{mg}$ or matching placebo orally twice daily. The mean age was 63 years. Most patients (90\%) had AF; $41 \%$ had structural heart disease; and NYHA class I or II HF was present in approximately $17 \%$ of patients (left ventricular ejection fraction approximately $60 \%$ ). Thus, the study population was relatively young and free from heart failure, although a substantial number of patients had structural heart disease (type not specified). Patients were followed for 12 months. ${ }^{43}$ The time to recurrence of AF (primary endpoint) was longer with dronedarone (116 days) than with placebo (53 days, $P$ value not reported). The rate of recurrence of AF after 12 months was 64.1\% with dronedarone and $75.2 \%$ with placebo $(P<0.001)$. The rate of hospitalization or death also was significantly lower in the dronedarone group (22.8\%) than in the placebo group $(30.9 \%, P=0.01)$. The only adverse event that was associated with dronedarone was elevation of serum creatinine, which occurred in $2.4 \%$ of patients treated with dronedarone and $0.2 \%$ of patients treated with placebo $(P=0.004)$.

The Antiarrythmic Trial with Dronedarone in Moderate to Severe CHF Evaluating Morbidity Decrease (ANDROMEDA) study had a planned enrollment of 1,000 patients hospitalized with symptomatic heart failure, moderate or severe left ventricular systolic dysfunction (NYHA class III or IV), and a left ventricular ejection fraction of $35 \%$ or less. ${ }^{44}$ The primary endpoint was a composite of death from any cause or hospitalization for heart failure. The study was terminated prematurely after 627 patients had enrolled (median of 2 months) because of a significantly higher rate of all-cause mortality in dronedarone-treated patients (8.1\%) compared with placebo-treated patients $(3.8 \%, P=0.03)$. Most of the deaths in the dronedarone group were cardiovascular deaths associated with worsening heart failure. There was no significant difference between dronedarone and placebo in the primary endpoint (53 events [17.1\%] with dronedarone and 40 events [12.6\%] with placebo, $P=0.12$ ).

The ATHENA (A Placebo-Controlled, Double-Blind, Parallel Arm Trial to Assess the Efficacy of Dronedarone $400 \mathrm{mg}$ bid for the Prevention of Cardiovascular Hospitalization or Death from any Cause in Patients with Atrial Fibrillation/Atrial Flutter) study involved 4,628 patients with paroxysmal or persistent AF who were (a) aged 70 years or older with hypertension managed with at least 2 antihypertensive medications from different classes; diabetes mellitus; previous stroke, transient ischemic attack, or systemic embolism; large left atrial diameter; or left ventricular ejection fraction of $40 \%$ or less; or (b) aged 75 years or older without any of these risk factors. ${ }^{45}$ Exclusion criteria included permanent AF, hemodynamic instability (decompensated heart failure within the previous 4 weeks), NYHA class IV heart failure (HF), bradycardia, and heart block. The mean age was 72 years. Structural heart disease was present in $60 \%$ of patients; $21 \%$ of patients had a history of heart failure (17\% with NYHA class II HF and $4 \%$ with NYHA class III HF); and $12 \%$ of patients had a left ventricular ejection fraction less than $45 \% .{ }^{45}$ Thus, the patients in this study were older and more likely to have structural heart disease compared with those in the EURIDIS and ADONIS studies, although heart failure was not common or severe in these 3 studies.

In ATHENA, the primary outcome was first hospitalization for a cardiovascular event or death. ${ }^{45}$ The mean duration of followup was 21 months (range 1-2.5 years). Compared with placebo, dronedarone was associated with a significantly lower incidence of the primary outcome ( $31.9 \%$ vs. $39.4 \%$ with placebo, $P<0.001$ ). Most of this difference was attributed to a significantly lower incidence of cardiovascular hospitalization in the dronedarone group compared with placebo ( $29.3 \%$ vs. $36.9 \%$, respectively, $P<0.001$ ), and this reduced incidence was driven mainly by a reduction in 
hospitalizations for AF (14.6\% with dronedarone vs. $21.9 \%$ with placebo, $P<0.001)$ and for acute coronary syndrome $(2.7 \%$ with dronedarone vs. $3.8 \%$ with placebo, $P=0.03$ ).

Adverse events reported by significantly more dronedaronetreated patients than placebo-treated patients in the ATHENA study included gastrointestinal events $(26.2 \%$ vs. $22.0 \%, P<0.001)$, elevation of serum creatinine ( $4.7 \%$ vs. $1.3 \%, P<0.001$ ), bradycardia (3.5\% vs. $1.2 \%, P<0.001)$, rash (3.4\% vs. $2.0 \%, P=0.006)$, and QT-interval prolongation (1.7\% vs. $0.6 \%, P<0.001) .{ }^{45}$ One case of torsades de pointes was reported in the dronedarone group. There was no significant difference between the dronedarone group and the placebo group in the incidence of pulmonary fibrosis, liver function test elevation, or thyroid dysfunction. Some of the patients were followed for a period as short as 1 year, and whether this duration was sufficient to detect the true incidence of the most serious adverse events might be questioned.

The efficacy for maintaining sinus rhythm and the safety of dronedarone and amiodarone were compared in the DIONYSOS (Efficacy \& Safety of Dronedarone Versus Amiodarone for the Maintenance of Sinus Rhythm in Patients With Atrial Fibrillation) study, which has yet to be published. ${ }^{46}$ Results presented in this article are only available from the manufacturer's press release. In this double-blind, parallel-group study, 504 patients with persistent $\mathrm{AF}$ were randomized to receive dronedarone $400 \mathrm{mg}$ orally twice daily or amiodarone $600 \mathrm{mg}$ per day orally for 28 days followed by $200 \mathrm{mg}$ per day orally. The primary endpoint was AF recurrence or premature study discontinuation for intolerance or lack of efficacy. After a mean follow-up of 7 months, the primary endpoint had been reached by significantly more patients in the dronedarone group (73.9\%) than patients in the amiodarone group (55.3\%, $P<0.001)$. The rate of recurrence of AF was 36.5\% with dronedarone and $24.3 \%$ with amiodarone $(P$ value not reported). There was no significant difference between treatment groups in the incidence of the predefined main safety endpoint, which included thyroid, hepatic, pulmonary, neurologic, skin, ocular, and gastrointestinal adverse events. Of note, neither pulmonary fibrosis nor liver toxicity was noted to occur in either group in this study, although the follow-up may not have been long enough to observe these adverse effects. ${ }^{47}$ The protocol also called for analysis of safety data excluding the gastrointestinal adverse events (e.g., diarrhea, vomiting, nausea), and the number of non-gastrointestinal adverse events was significantly lower in dronedarone-treated patients (61) than in amiodarone-treated patients $(99, P=0.002)$.

The results of dronedarone studies conducted to date suggest that the drug should not be used in patients with moderate or severe heart failure. While the precise language for the explicit label indications for dronedarone were unclear at the time that this article was prepared, dronedarone will have a black-box warning against the use of this drug in patients with severe heart failure. Dronedarone is effective for maintaining sinus rhythm in patients with $\mathrm{AF}$, albeit possibly less so than amiodarone.
However, dronedarone may have some safety advantage over amiodarone, since the occurrence of pulmonary fibrosis, liver dysfunction, and thyroid dysfunction with dronedarone has been shown to be similar to placebo.43

In mid-2009, the role of dronedarone in the care of patients with AF is evolving. Publication of the results of the DIONYSOS study and future clinical trials will provide additional insight into the efficacy and safety of the drug compared with currently available antiarrhythmic agents. Studies with a longer duration than those conducted to date may be needed to provide an accurate assessment of drug tolerability. In March 2009, the FDA Cardiovascular and Renal Drugs Advisory Committee recommended approval of dronedarone in patients with persistent or paroxymal AF who have an ejection fraction greater than $35 \%, 47,48$ and the FDA approved dronedarone for use in the United States on July 2, 2009. According to information released by the FDA, the specific label will indicate that dronedarone is "approved to help maintain normal heart rhythms in patients with a history of atrial fibrillation or atrial flutter (heart rhythm disorders). The drug is approved to be used in patients whose hearts have returned to normal rhythm or who will undergo drug or electricshock treatment to restore a normal heart beat. Dronedarone may cause critical adverse reactions, including death, in patients with recent severe heart failure."49 The drug's label will contain a boxed warning, the FDA's strongest warning, cautioning that the drug should not be used in severe heart failure patients. ${ }^{49}$

\section{Vernakalant}

Vernakalant is a mixed sodium and potassium channel blocker currently under review by FDA for acute conversion of AF. It is available in both intravenous and oral forms. Phase III studies comparing the intravenous formulation with placebo for acute cardioversion in patients with recent-onset AF have found that the drug significantly improves the likelihood of restoring sinus rhythm (45\% vs. 15\%, P<0.001). ${ }^{50}$ Most patients included in these studies had AF of recent onset ( $<7$ days). Conversion rates in these studies ranged from $45 \%$ to $61 \%$ with the most commonly used regimen ( $2 \mathrm{mg}$ per $\mathrm{kg}$ vernakalant followed by $3 \mathrm{mg}$ per kg 30 minutes later if AF continues). ${ }^{46}$ Conversion rate was greater than with placebo, yet much lower (6\% to $9 \%$ ) in studies that included patients with onset of AF within 8 to 45 days. ${ }^{50,51}$

An oral formulation has been evaluated for the maintenance of sinus rhythm in patients with AF in phase II, placebo-controlled, dose-ranging studies, with promising results achieved with the use of $300 \mathrm{mg}$ or $600 \mathrm{mg}$ twice daily. ${ }^{50}$ Commonly reported adverse effects during vernakalant treatment include dysgeusia, sneezing, and paresthesia. Proarrhythmia with the use of vernakalant have not been reported to date and will be important in weighing the risks versus the benefits of this agent. The FDA Cardiovascular and Renal Drugs Advisory Committee has recommended approval of intravenous vernakalant. ${ }^{52}$ 


\section{- Future Directions in Antiarrhythmic Development}

Study of both azimilide and tedisamil for treatment of AF has also been undertaken. However, it is unlikely that either of these agents will be approved in the future for use in patients with AF. While azimilide was found to be safe in patients with structural heart disease in the Azimilide Post Infarct Survival Evaluation (ALIVE), ${ }^{53}$ the drug does not appear to be efficacious for maintenance of sinus rhythm in patients with either paroxysmal or persistent AF. ${ }^{54-56}$ Tedisamil was submitted to the FDA for approval as a treatment for acute pharmacologic conversion of AF. While this drug demonstrated efficacy similar to other antiarrhythmic medications for acute conversion, safety concerns led the FDA Advisory Panel to recommend against approval of tedisamil. ${ }^{13}$

Other medications under development for treatment of AF are mostly in the earlier stages of development. The pharmacologic targets of most experimental agents for AF are potassium channels other than the rapid delayed inward rectifying potassium channel $\left(\mathrm{I}_{\mathrm{Kr}}\right)$. Most commonly, drugs targeting the ultra-rapid delayed inward rectifying potassium channel $\left(\mathrm{I}_{\text {Kur }}\right)$ are being developed. ${ }^{57}$ Targeting this channel may allow for antiarrhythmic efficacy with fewer proarrhythmic side effects, since these channels are mainly found in atrial tissues. ${ }^{56}$

\section{Wonantiarrhythmic Agents}

Activation of the renin-angiotensin-aldosterone system has been proposed as a contributing factor in $\mathrm{AF} .{ }^{1}$ Re-analysis of data from randomized controlled studies of angiotensin-converting enzyme (ACE) inhibitors and angiotensin receptor blockers (ARBs) found a significant reduction in the risk of new-onset AF from the use of these drugs compared with placebo or active control (e.g., a $\beta$-blocker). ${ }^{58-62}$ Pooling data from other controlled studies of patients with AF revealed lower rates of AF recurrence after cardioversion associated with the use of ACE inhibitors or ARBs usually in combination with amiodarone compared with placebo or with amiodarone alone (odds ratio $=0.39, P=0.005$ ). ${ }^{58,62,63,64,66}$ Additional research is needed to clarify the role of ACE inhibitors and ARBs in preventing AF and maintaining sinus rhythm after cardioversion in patients with AF. Neither of these uses of ACE inhibitors or ARBs is approved by the FDA.

\section{Oral Anticoagulants}

Rivaroxaban, a factor Xa inhibitor, and dabigatran, a direct thrombin inhibitor, are investigational oral anticoagulant agents that have been used successfully to prevent venous thromboembolism (VTE) in patients undergoing orthopedic surgery. ${ }^{67}$ Clinical trials of these agents for the prevention of embolic stroke in patients with AF are also in progress. Rivaroxaban and dabigatran offer several potential advantages over warfarin. Neither of these agents requires the close laboratory monitoring that is required during warfarin therapy. Rivaroxaban and dabigatran also have more predictable pharmacodynamics than warfarin, which should facilitate dosing. In March 2009, the
FDA Cardiovascular and Renal Drugs Advisory Committee recommended approval of rivaroxaban for the prophylaxis of VTE in patients undergoing hip- and knee-replacement surgery. ${ }^{68}$ FDA approval of dabigatran is not anticipated before 2010. While data with these agents are not yet available, studies are ongoing. Therefore, these agents could emerge as an alternative to long-term anticoagulation with warfarin in patients with AF. Pharmacoeconomic considerations will need to be assessed in addition to efficacy and safety issues when these new anticoagulants are evaluated for the management of AF.

\section{Conclusions}

Although rate-control strategies are currently favored in patients with AF, rhythm-control strategies are required for some patients. The choice among antiarrhythmic drug therapies is based on patient-specific characteristics. Emerging antiarrhythmic agents with potentially improved safety and anticoagulants that require less frequent monitoring than warfarin may become therapeutic options in the future. The role of these new agents will be clearer in the future as data regarding the relative efficacy, safety, and economic impact of these drugs become available. The preference for rate-control strategies over rhythm-control strategies could change if antiarrhythmic agents with improved tolerability are introduced.

\section{REFERENCES}

1. Fuster V, Rydén LE, Cannom DS, et al. ACC/AHA/ESC 2006 Guidelines for the Management of Patients with Atrial Fibrillation: a report of the American College of Cardiology/American Heart Association Task Force on Practice Guidelines and the European Society of Cardiology Committee for Practice Guidelines (Writing Committee to Revise the 2001 Guidelines for the Management of Patients With Atrial Fibrillation): developed in collaboration with the European Heart Rhythm Association and the Heart Rhythm Society. Circulation. 2006;114(7):e257-354. Available at: http://circ.ahajournals.org/cgi/reprint/114/7/e257. Accessed July 23, 2009.

2. Gage BF, Waterman AD, Shannon W, Boechler M, Rich MW, Radford MJ. Validation of clinical classification schemes for predicting stroke: results from the National Registry of Atrial Fibrillation. JAMA. 2001;285(22):286470. Available at: http://jama.ama-assn.org/cgi/reprint/285/22/2864. Accessed July 23, 2009

3. Singer DE, Albers GW, Dalen JE, et al. Antithrombotic therapy in atrial fibrillation: American College of Chest Physicians Evidence-Based Clinical Practice Guidelines (8th edition). Chest. 2008;133(6 Suppl):546S-92S. Available at: http://www.chestjournal.org/content/133/6_suppl/546S.full. pdf + html. Accessed July 23, 2009.

4. Wyse DG, Waldo AL, DiMarco JP, et al.; AFFIRM Investigators. A comparison of rate control with rhythm control in patients with atrial fibrillation. N Engl J Med. 2002;347(23):1825-33. Available at: http://content.nejm. org/cgi/reprint/347/23/1825.pdf. Accessed July 23, 2009

5. Hagens VE, Ranchor AV, Van Sonderen E, et al. Effect of rate or rhythm control on quality of life in persistent atrial fibrillation. Results from the Rate Control Versus Electrical Cardioversion (RACE) Study. J Am Coll Cardiol. 2004:43(2):241-47. Available at: http://content.onlinejacc.org/cgi/ reprint/43/2/24l.pdf. Accessed July 23, 2009. 
6. Grönefeld GC, Lilienthal J, Kuck KH, Hohnloser SH, Pharmacologic Intervention in Atrial Fibrillation (PIAF) Study investigators. Impact of rate versus rhythm control on quality of life in patients with persistent atrial fibrillation. Results from a prospective randomized study. Eur Heart J. 2003;24(15):1430-36. Available at: http://eurheartj.oxfordjournals.org/cgi/ reprint/24/15/1430. Accessed July 23, 2009.

7. Coyne KS, Paramore C, Grandy S, Mercader M, Reynolds M, Zimetbaum P. Assessing the direct costs of treating nonvalvular atrial fibrillation in the United States. Value Health. 2006;9(5):348-56.

8. Choudhry NK, Zagorski B, Avorn J, et al. Comparison of the impact of the Atrial Fibrillation Follow-Up Investigation of Rhythm Management trial on prescribing patterns: a time-series analysis. Ann Pharmacother. 2008;42(11):1563-72.

9. Roy D, Talajic M, Nattel S, et al. Rhythm control versus rate control for atrial fibrillation and heart failure. N Engl J Med. 2008;358(25):2667-77. Available at: http://content.nejm.org/cgi/reprint/358/25/2667.pdf. Accessed July 23, 2009.

10. King DE, Dickerson LM, Sack JL. Acute management of atrial fibrillation: Part I. Rate and rhythm control. Am Fam Physician. 2002;66(2):249-56. Available at: http://www.aafp.org/afp/20020715/249.pdf. Accessed July 23, 2009.

11. Tabery S, Bouwels L, Uijen GJH, Uppelschoten A, Verheugt FWA. Factors influencing immediate and long-term outcome of electrical cardioversion of persistent atrial fibrillation and flutter. Neth Heart J. 2001;9(1):1622. Available at: http://www.pubmedcentral.nih.gov/picrender.fcgi?artid=249 9578\&blobtype=pdf. Accessed July 23, 2009.

12. Van Gelder IC, Tuinenburg AE, Schoonderwoerd BS, Tieleman RG, Crijns HJ. Pharmacologic versus direct-current electrical cardioversion of atrial flutter and fibrillation. Am J Cardiol. 1999;84(9A):147R-51R.

13. Hiatt WR, Lincoff A, Harrington RA. Acute pharmacological conversion of atrial fibrillation to sinus rhythm: is short-term therapy worth it? A report from the December 2007 meeting of the Cardiovascular and Renal Drugs Advisory Committee of the Food and Drug Administration. Circulation. 2008;117(22):2956-57. Available at: http://circ.ahajournals.org/ cgi/reprint/117/22/2956. Accessed July 26, 2009.

14. Norpace [package insert]. Chicago, IL: G.D. Searle LLC; September 2001 http://www.pfizer.com/files/products/uspi_norpace.pdf. Accessed July 23, 2009.

15. McEvoy GK, ed. Quinidine gluconate/quinidine sulfate. In: AHFS Drug Information 2009. Bethesda, MD: American Society of Health-System Pharmacists; 2009:1652-57.

16. The Cardiac Arrhythmia Suppression Trial (CAST) Investigators. Preliminary report: effect of encainide and flecainide on mortality in a randomized trial of arrhythmia suppression after myocardial infarction. N Engl J Med. 1989;321(6):406-12.

17. Rythmol [package insert]. Liberty Corner, NJ: Reliant Pharmaceuticals, Inc.; September 2004. Available at: http://us.gsk.com/products/assets/ us_rythmol.pdf. Accessed July 23, 2009.

18. McEvoy GK, ed. Propafenone hydrochloride. In: AHFS Drug Information 2009. Bethesda, MD: American Society of Health-System Pharmacists; 2009:1671-82.

19. Fang MC, Stafford RS, Ruskin JN, Singer DE. National trends in antiarrhythmic and antithrombotic medication use in atrial fibrillation. Arch Intern Med. 2004;164(1):55-60. Available at: http://archinte.ama-assn.org/cgi/ reprint/164/1/55. Accessed July 23, 2009.

20. Cordarone [package insert]. Philadelphia, PA: Wyeth Pharmaceuticals Inc.; May 2009. Available at: http://www.wyeth.com/content/showlabeling. asp?id=93. Accessed July 23, 2009.
21. Singh SN, Fletcher RD, Fisher SG, et al. Amiodarone in patients with congestive heart failure and asymptomatic ventricular arrhythmia. Survival Trial of Antiarrhythmic Therapy in Congestive Heart Failure. N Engl J Med. 1995;333(2):77-82. Available at: http://content.nejm.org/cgi/ reprint/333/2/77.pdf. Accessed July 23, 2009.

22. Massie BM, Fisher SG, Radford M, et al., for the CHF-STAT Investigators. Effect of amiodarone on clinical status and left ventricular function in patients with congestive heart failure. Circulation. 1996;93(12):212834. Available at: http://circ.ahajournals.org/cgi/content/full/93/12/2128. Accessed July 23, 2009.

23. Doval HC, Nul DR, Grancelli HO, Perrone SV, Bortman GR, Curiel R. Randomised trial of low-dose amiodarone in severe congestive heart failure. Grupo de Estudio de la Sobrevida en la Insuficiencia Cardiaca en Argentina (GESICA). Lancet. 1994;344(8921):493-98,

24. Bardy GH, Lee KL, Mark DB, et al for the Sudden Cardiac Death in Heart Failure Trial (SCD-HeFT) Investigators. Amiodarone or an implantable cardioverter-defibrillator for congestive heart failure. N Engl J Med. 2005;352(3):225-37. Available at: http://content.nejm.org/cgi/ reprint/352/3/225.pdf. Accessed July 23, 2009.

25. McEvoy GK, ed. Amiodarone hydrochloride. In: AHFS Drug Information 2009. Bethesda, MD: American Society of Health-System Pharmacists; 2009:1682-97.

26. Yamreudeewong W, DeBisschop M, Martin LG, Lower DL. Potentially significant drug interactions of class III antiarrhythmic drugs. Drug Saf. 2003;26(6):421-38.

27. Betapace AF [package insert]. Wayne, NJ: Bayer HealthCare Pharmaceuticals; April 2007. Available at: http://berlex.bayerhealthcare.com/ html/products/pi/BetapaceAF_PI.pdf. Accessed July 23, 2009.

28. McEvoy GK, ed. Sotalol hydrochloride. In: AHFS Drug Information 2009. Bethesda, MD: American Society of Health-System Pharmacists; 2009:192834

29. Pedersen OD, Brendorp B, Elming H, Pehrson S, Køber L, Torp-Pedersen $C$. Does conversion and prevention of atrial fibrillation enhance survival in patients with left ventricular dysfunction? Evidence from the Danish Investigations of Arrhythmia and Mortality ON Dofetilide/(DIAMOND) study. Card Electrophysiol Rev. 2003;7(3):220-24.

30. McEvoy GK, ed. Dofetilide. In: AHFS Drug Information 2009. Bethesda, MD: American Society of Health-System Pharmacists; 2009:1697-98.

31. Torp-Pedersen C, Møller M, Block-Thomsen PE, et al. Dofetilide in patients with congestive heart failure and left ventricular dysfunction. Danish Investigations of Arrhythmia and Mortality on Dofetilide Study Group. N Engl J Med. 1999;341(12):857-65. Available at: http://content.nejm. org/cgi/reprint/341/12/857.pdf. Accessed July 23, 2009.

32. Kalus JS, Mauro VF. Dofetilide: a class III-specific antiarrhythmic agent. Ann Pharmacother. 2000;34(1):44-6.

33. Tikosyn [package insert]. New York, NY: Pfizer Labs; March 2004. http://www.tikosyn.com/pdf/PI_tikosyn.pdf. Accessed July 23, 2009.

34. Lafuente-Lafuente C, Mouly S, Longas-Tejero MA, et al. Antiarrhythmics for maintaining sinus rhythm after cardioversion of atrial fibrillation. Cochrane Database Syst Rev. 2007 Oct 17;(4):CD005049.

35. Kochiadakis GE, Igoumenidis NE, Hamilos ME, et al. Sotalol versus propafenone for long-term maintenance of normal sinus rhythm in patients with recurrent symptomatic atrial fibrillation. Am J Cardiol. 2004;94(12):1563-66.

36. Singh BN, Singh SN, Reda DJ, et al. Amiodarone versus sotalol for atrial fibrillation. N Engl J Med. 2005;352(18):1861-72. Available at: http://content. nejm.org/cgi/reprint/352/18/1861.pdf. Accessed July 23, 2009.

37. Kochiadakis GE, Igoumenidis NE, Hamilos MI, et al. Long-term maintenance of normal sinus rhythm in patients with current symptomatic atrial fibrillation: amiodarone vs. propafenone, both in low doses. Chest. 2004;125(2):377-83. Available at: http://www.chestjournal.org/content/125/2/377.full.pdf+html. Accessed July 23, 2009. 
38. Alboni P, Botto GL, Baldi N, et al. Outpatient treatment of recentonset atrial fibrillation with the "pill-in-the-pocket" approach. $N$ Engl J Med. 2004;351(23):2384-91. Available at: http://content.nejm.org/cgi/ reprint/351/23/2384.pdf. Accessed July 23, 2009.

39. Sun W, Sarma JS, Singh BN. Electrophysiological effects of dronedarone (SR33589), a noniodinated benzofuran derivative, in the rabbit heart: comparison with amiodarone. Circulation. 1999;100(22):2276-81. Available at: http://circ.ahajournals.org/cgi/reprint/100/22/2276. Accessed July 26, 2009.

40. Laughlin JC, Kowey PR. Dronedarone: a new treatment for atrial fibrillation. J Cardiovasc Electrophysiol. 2008;19(11):1220-26.

41. Dale KM, White CM. Dronedarone: an amiodarone analog for the treatment of atrial fibrillation and atrial flutter. Ann Pharmacother. 2007;41(4):599-605.

42. Damy T, Pousset F, Caplain H, Hulot JS, Lechat P. Pharmacokinetic and pharmacodynamic interactions between metoprolol and dronedarone in extensive and poor CYP2D6 metabolizers healthy subjects. Fundam Clin Pharmacol. 2004;18(1):113-23.

43. Singh BN, Connolly SJ, Crijns HJ, et al. Dronedarone for maintenance of sinus rhythm in atrial fibrillation or flutter. N Engl J Med. 2007;357(10):98799. Available at: http://content.nejm.org/cgi/reprint/357/10/987.pdf. Accessed July 23, 2009.

44. Køber L, Torp-Pedersen C, McMurray JJ, et al. Increased mortality after dronedarone therapy for severe heart failure. N Engl J Med. 2008;358(25):2678-87. Available at: http://content.nejm.org/cgi/ reprint/358/25/2678.pdf. Accessed July 23, 2009.

45. Hohnloser SH, Crijns HJ, van Eickels M, et al., for the ATHENA Investigators. Effect of dronedarone on cardiovascular events in atrial fibrillation. N Engl J Med. 2009;360(7):668-78. Available at: http://content.nejm. org/cgi/reprint/360/7/668.pdf. Accessed July 26, 2009.

46. sanofi-aventis. DIONYSOS study results showed the respective profiles of dronedarone and amiodarone. December 23, 2008. Available at: http:// en.sanofi-aventis.com/press/press_releases/2008/ppc_23625.asp. Accessed July 23, 2009.

47. Zimetbaum PJ. Dronedarone for atrial fibrillation—an odyssey. N Engl J Med. 2009;360(18):1811-13.

48. Anonymous. FDA advisory committee recommends approval of Multaq (dronedarone). Medical News Today. March 19, 2009. Available at: http:// www.medicalnewstoday.com/articles/142834.php. Accessed July 26, 2009.

49. U.S. Food and Drug Administration. FDA approves Multaq to treat heart rhythm disorder. July 2, 2009. Available at: http://www.fda.gov/NewsEvents/ Newsroom/PressAnnouncements/ucm170276.htm. Accessed July 31, 2009.

50. Cheng JW. Vernakalant in the management of atrial fibrillation. Ann Pharmacother. 2008;42(4):533-42.

51. Roy D, Pratt CM, Torp-Pedersen D, et al. Vernakalant hydrochloride for rapid conversion of atrial fibrillation: a phase 3 , randomized, placebo-controlled trial. Circulation. 2008;117:1518-25. Available at: http://circ.ahajournals.org/cgi/content/full/117/12/1518. Accessed July 23, 2009.

52. Wood S. Advisory panel recommends approval of vernakalant for AF. December 12, 2007. Available at: http://www.theheart.org/article/833263.do. Accessed April 8, 2009.

53. Pratt CM, Singh SN, Al-Khalidi HR, Brum JM, et al. The efficacy of azimilide in the treatment of atrial fibrillation in the presence of left ventricular systolic dysfunction: Results from the Azimilide Postinfarct Survival Evaluation (ALIVE) trial. J Am Coll Cardiol. 2004;43(7):1211-16. Available at: http://content.onlinejacc.org/cgi/reprint/43/7/1211. Accessed July 23, 2009.

54. Pritchett EL Kowey P, Connolly S, et al. Antiarrhythmic efficacy of azimilide in patients with atrial fibrillation. Maintenance of sinus rhythm after conversion to sinus rhythm. Am Heart J. 2006;151(5):1043-49.
55. Lombardi F, Borggrefe M, Ruzyllo W, Luderitz B; A-COMET- II Investigators. Azimilide vs. placebo and sotalol for persistent atrial fibrillation: the A-COMET-II (Azimilide-CardiOversion MaintEnance Trial-II) trial. Eur Heart J. 2006;27(18):2224-31. Available at: http://eurheartj.oxfordjournals.org/cgi/reprint/27/18/2224. Accessed July 23, 2009.

56. Kerr CR, Connolly SJ, Kowey P, et al. Efficacy of azimilide for the maintenance of sinus rhythm in patients with paroxysmal atrial fibrillation in the presence and absence of structural heart disease. Am J Cardiol. 2006;98(2):215-18.

57. Camm AJ, Savelieva I. New antiarrhythmic drugs for atrial fibrillation: focus on dronedarone and vernakalant. J Interv Cardiol Electrophys. 2008;23(1):7-14

58. Kalus JS, Coleman CI, White CM. The impact of suppressing the reninangiotensin system on atrial fibrillation. J Clin Pharmacol. 2006;46(1):21-28.

59. Pedersen OD, Bagger H, Kober L, Torp-Pedersen C. Trandolapril reduces the incidence of atrial fibrillation after acute myocardial infarction in patients with left ventricular dysfunction. Circulation. 1999;100(4):376-80. Available at: http://circ.ahajournals.org/cgi/reprint/100/4/376. Accessed July 23, 2009.

60. Vermes E, Tardif JC, Bourassa MG, et al. Enalapril decreases the incidence of atrial fibrillation in patients with left ventricular dysfunction: insight from the Studies of Left Ventricular Dysfunction (SOLVD) trials. Circulation. 2003;107(23):2926-31. Available at: http://circ.ahajournals.org/ cgi/reprint/107/23/2926. Accessed July 26, 2009.

61. Maggioni AP, Latini R, Carson PE, et al. Valsartan reduces the incidence of atrial fibrillation in patients with heart failure: results from the Valsartan Heart Failure Trial (Val-HeFT). Am Heart J. 2005;149(3):548-57.

62. Wachtell K, Lehto M, Gerdts E, et al. Angiotensin II receptor blockade reduces new-onset atrial fibrillation and subsequent stroke compared to atenolol: the Losartan Intervention For End Point Reduction in Hypertension (LIFE) study. J Am Coll Cardiol. 2005;45(5):712-19. Available at: http://content.onlinejacc.org/cgi/reprint/45/5/712.pdf. Accessed July 23, 2009.

63. Van Den Berg MP, Crijns HJ, Van Veldhuisen DJ, Griep N, De Kam PJ, Lie KI. Effects of lisinopril in patients with heart failure and chronic atrial fibrillation. J Card Fail. 1995;1(5):355-63.

64. Madrid AH, Bueno MG, Rebollo JM, et al. Use of irbesartan to maintain sinus rhythm in patients with long-lasting persistent atrial fibrillation: a prospective and randomized study. Circulation. 2002;106(3):331-36. Available at: http://circ.ahajournals.org/cgi/reprint/106/3/331. Accessed July 23, 2009.

65. Madrid AH, Marin IM, Cervantes CE, et al. Prevention of recurrences in patients with lone atrial fibrillation. The dose-dependent effect of angiotensin II receptor blockers. J Renin Angiotensin Aldosterone Syst. 2004;5(3):114-20. Available at: http://jra.sagepub.com/cgi/reprint/5/3/114. Accessed July 23, 2009.

66. Ueng KC, Tsai TP, Yu WC, et al. Use of enalapril to facilitate sinus rhythm maintenance after external cardioversion of long-standing persistent atrial fibrillation. Results of a prospective and controlled study. Eur Heart J. 2003;24(23):2090-98. Available at: http://eurheartj.oxfordjournals.org/cgi/ reprint/24/23/2090. Accessed July 23, 2009.

67. Turpie AG. New oral anticoagulants in atrial fibrillation. Eur Heart J. 2008;29(2):155-65. Available at: http://eurheartj.oxfordjournals.org/cgi/ reprint/29/2/155. Accessed July 23, 2009.

68. Walker EP. Rivaroxaban recommended for approval by FDA advisory panel. Medpage Today. March 19, 2009. Available at: http://www.medpagetoday.com/ProductAlert/Prescriptions/13353. Accessed July 24, 2009. 